\title{
Т.С. Паршикова
}

\section{АРХЕОЛОГИЧЕСКОЕ НАСЛЕДИЕ АЛТАЯ: ИЗУЧЕНИЕ И СОХРАНЕНИЕ В 1940-1960-е гг. ${ }^{1}$}

\begin{abstract}
Представлены результаты мероприятий по охране памятников археологии на Алтае в 1940-1960-е г2., в том числе данные по учету и паспортизачии объектов. В это время актуальным становится вопрос формирования законодательной базы в данной области. Приводятся данные о работе по выявлению, регистрации, составлению списков и паспортизации памятников истории и культуры, а также освещается деятельность Всероссийского общества охраны памятников истории и культуры в Алтайском крае на начальном этапе (в коние 1960-х гг.)

Ключевые слова: археология, Алтай, историко-культурное наследие, экспедиции, охрана памятников, ВООПИК.
\end{abstract}

На территории нашей страны сконцентрировано значительное количество ценных объектов историко-культурного наследия. Многие из них поистине уникальны и могут быть отнесены к мировым сокровищам культуры. Важное направление в деле охраны историко-культурного наследия - выявление, систематизация, изучение и сохранение памятников археологии.

В конце 1940-х гг., после окончания Великой Отечественной войны, вопрос сохранения наследия стал особенно актуальным. Руководством страны отмечалось, что в деле охраны памятников культуры имеются серьезные недостатки. В связи с этим 14 октября 1948 г. вышло постановление Совета Министров СССР № 3898 «О мерах по улучшению охраны памятников культуры» [1. С. 136-144], утверждающее Положение об охране памятников культуры, по которому местным органам власти предписывалось:

1. Осуществлять надзор за тем, чтобы археологические разведки и раскопки производились лицами, имеющими на то право в соответствии с полученными ими разрешениями («Открытыми листами»).

2. Не допускать использования памятников в каких-либо хозяйственных целях (в качестве строительного материала, а также распашки или разрытия).

3. Установить вокруг археологических памятников охранные зоны.

4. Решительно пресекать самовольные раскопки и другие действия, влекущие разрушение археологических памятников [2. С. 77-78].

23 ноября 1948 г. исполнительный комитет Алтайского краевого Совета депутатов трудящихся вынес решение № 822 «Об охране памятников культуры на территории Алтайского края». Согласно Положению государствен-

${ }^{1}$ Работа выполнена при поддержке гранта Министерства образования и науки РФ (постановление № 220), полученного ФГБОУ ВПО «Алтайский государственный университет», проект № 2013220-04-129 «Древнейшее заселение Сибири: формирование и динамика культур на территории Северной Азии», а также в рамках базовой части государственного задания Алтайского государственного университета «Использование естественно-научных методов в реконструкции историко-культурных процессов на Алтае в древности» (код проекта 1006). 
ной охране подлежали памятники архитектуры, памятники искусства, памятники археологии, исторические памятники [1. С. 136-144].

Постановлением Совета Министров от 28 мая 1949 г. № 373 была утверждена Инструкция о порядке учета, регистрации и содержания археологических и исторических памятников на территории РСФСР. Согласно ей на территории Алтайского края проводились работы по выявлению, регистрации, составлению списков и паспортизации памятников археологии. Регулирование данной деятельности осуществлялось отделом культурнопросветительской работы крайисполкома, Горно-Алтайским облисполкомом, городскими, районными и сельскими исполнительными комитетами. Краеведческие музеи (Алтайский краевой краеведческий музей, Бийский краеведческий музей, Горно-Алтайский областной краеведческий музей, Каменский краеведческий музей, районные музеи) были ответственными за выполнение работ как наиболее компетентные организации в данной области [2. С. 77].

Основное внимание в то время уделялось объектам историко-революционного характера (братским могилам, обелискам, памятникам Гражданской войны). В списке памятников республиканского значения, находящихся на территории Алтайского края (1949 г.), археологические объекты не значились. Однако работы по их учету велись.

Необходимо отметить, что археологические изыскания, проводимые в данный период на Алтае сотрудниками центральных научных учреждений страны и местными центрами $[3,4,5]$, существенным образом способствовали включению объектов археологического наследия во вновь создаваемые охранные списки. В конце 1949 г. в перечне учтенных и запаспартизированных памятников Алтая обозначено 57 позиций, среди которых № 19 - комплекс памятников в урочище Ближние Елбаны, № 26 - тюркское изваяние «Кезер», № 35 - пять «царских» курганов урочища Пазырык, № 36 - древний оросительный канал в Курайской степи (Кош-Агачский район) и др. [6. Л. 86].

Одновременно с осуществлением государственного учета и паспортизации определялись охранные зоны исторических и археологических памятников. Согласно Инструкции на каждый объект составлялись Акт технического осмотра и Охранное обязательство. Ответственность за сохранность памятников возлагалась на местные Советы, колхозы и организации, на территории которых они располагались. Все учтенные объекты утверждались районными и городскими исполкомами с указанием размеров охранных зон, режима использования и персональной ответственности за их сохранность. Паспортизацией охватывались из учтенных лишь те памятники, данные о которых отвечали указанным требованиям. По этой причине паспорта были составлены на 180 исторических и 57 археологических памятников, тогда как учтено соответственно 253 и 66 [7. Л. 80-82].

В документах отмечается, что при работе по учету объектов музеи обращались за помощью к археологам из центральных научных учреждений. Так, например, М.П. Грязнов неоднократно осматривал археологическую коллекцию АККМ, которая была выставлена на одной витрине и включала материалы, полученные в разные годы с территории края, вносил необходимые поправки в определение отдельных предметов [8. Л. 16]. А.П. Уманский в своих воспоминаниях указывал на то, что при содействии М.П. Грязнова одним из 
первых был составлен паспорт на комплекс памятников урочища Ближние Елбаны [9. С. 184]. Что касается работавшего в это время на территории Горного Алтая С.И. Руденко, то, как отмечается в отчете ГАОКМ за 1949 г., ученый часто посещал музей и давал консультации относительно размещения предметов и составления сопроводительных текстов [10. Л. 17].

В отчете о работе музеев и охране памятников за 1950 г. [11. Л. 70] отмечалось, что археологические комплексы, представленные древними курганами, стоянками, городищами, каменными изваяниями и другими объектами, выявлены на территории Горно-Алтайской автономной области, Быстроистокинского, Сросткинского, Старобардинского, Топчихинского, Усть-Пристанского районов и в окрестностях г. Бийска. Наибольшее количество объектов было зафиксировано в Онгудайском, Улаганском, Кош-Агачском и Шебалинском аймаках. Учтенные археологические памятники были обследованы и в ряде случаев частично раскопаны. Для изучения отдельных объектов организовывались научные командировки работников музеев. Они на местах уточняли имеющиеся данные, составляли характеристики, определяли топографическое положение.

В конце 1950-х гг. внимание стало уделяться памятникам, находившимся в аварийном состоянии. Управление музеев и охраны памятников Министерства культуры СССР запрашивало у местных органов информацию о памятниках археологии, подвергавшихся разрушению (распашка, размывка реками и т.д.). Так, на охрану памятников истории, археологии и искусства в 1959 г. краю выделялось 315 тысяч рублей, 35 из которых предназначались на исследование объектов древней истории, находившихся в аварийном состоянии [12. Л. 13-14].

В начале 1960-х гг. в СССР государственные и общественные институты столкнулись с целым комплексом проблем, связанных с изучением, сохранением и использованием памятников. Серьезные недостатки в работе, связанной с охраной объектов историко-культурного наследия, стали предметом аналитического обзора, выполненного в 1963 г. Управлением изобразительных искусств и охраны памятников Министерства культуры СССР. В нем, в частности, отмечались факты массового уничтожения и порчи исторических, архитектурных, художественных и революционных объектов наследия в связи с проведением реконструкций исторических центров советских городов и проявлением халатности на местах. Среди причин неудовлетворительной памятникоохранительной работы учреждений назывались: отсутствие четкой системы и слабая связь между государственными и общественными институтами. Авторы обзора считали, что весь комплекс охранных мероприятий не может быть обеспечен только государственными органами охраны наследия [13. С. 18].

В целях привлечения широкой общественности к активному участию в деле охраны памятников истории и культуры постановлением Совета Министров РСФСР № 882 от 23 июля 1965 г. было организовано Всероссийское общество охраны памятников истории и культуры (ВООПИК). Летом 1966 г. в Москве прошла учредительная конференция [14. Л. 20-27]. Организация стала первой неправительственной структурой в сфере сохранения наследия, объединявшей в своих рядах не только краеведов-любителей, но прежде все- 
го специалистов: архитекторов, историков, искусствоведов, музейных и архивных работников, реставраторов, инженеров-технологов, археологов.

В июле 1966 г. Президиумом Центрального Совета (ЦС) Общества утверждены местные отделения [14. Л. 13]. В постановлении от 5 июля 1966 г. под № 3 обозначено Алтайское краевое отделение, председателем которого являлся П.А. Бородкин (заведующий архивным отделом крайисполкома), а председателем Алтайского краевого Совета ВООПИК стал Н.Н. Первушин (председатель правления Алтайской организации Союза архитекторов СССР) [14. Л. 14]. Тогда же (в июле 1966 г.) сформирована Государственная инспекция по охране памятников. В ее состав вошли три отдела: охраны, реставрации, эксплуатации и пропаганды.

Среди приоритетных оставались вопрос учета памятников, а также проблема отсутствия квалифицированных специалистов, способных проводить весь комплекс мероприятий по выявлению, изучению, сохранению и популяризации объектов наследия. В связи с этим 13 мая 1967 г. Комиссия археологических памятников ЦС ВООПИК и Отдел полевых исследований Института археологии АН СССР обратились с просьбой к археологам, выезжавшим летом в регионы СССР для проведения исследований памятников археологии, оказывать местным отделениям ВООПИК помощь по выявлению, учету и охране археологических объектов [15. Л. 67].

В 1967 г. ко всем выдаваемым Открытым листам шло Приложение следующего содержания:

Уважаемые товарищи! Созданное в 1966 г. Всероссийское общество охраны памятников истории и культуры, в целях оказания помощи государственным органам в сохранении исторического и культурного наследия народов нашей Родины, проводит работу по выявлению, учету, организации охраны и популяризации памятников истории и культуры, в том числе и памятников археологии.

Однако местные отделения Общества зачастую испытывают трудности в работе из-за отсутствия специалистов-археологов. Мы обращаемся к Вам с большой просьбой оказать квалифицированную помощь отделению Общества, находящемуся в области, где Вы проводите исследования.

Как специалист Вы можете помочь в решении многих вопросов, в том числе:

- в выявлении еще не учтенных памятников археологии;

- в определении научной ценности памятника с целью включения его в списки памятников общесоюзного, республиканского или местного значения;

- в составлении паспортов на вновь выявленные археологические памятники и проверке паспортов на ранее учтенные памятники;

- в определении охранной зоны археологического памятника;

- в составлении охранного обязательства на археологический памятник;

- в составлении карты археологических памятников того или иного района;

- в популяризации археологических памятников исследуемой Вами области через местную печать, радио, телевидение, путем проведения экскурсий, бесед, чтения лекций и т.п.

Заведующая Отделом полевых исследований Института археологии АН СССР - Л. Евтюхова. Председатель Комиссии археологических памятников ЦС ВООПИК - Е. Крупнов [15. Л. 68]. 
На территории Алтайского края консультации местным отделениям Общества давали А.П. Окладников, С.С. Сорокин, А.П. Уманский, Б.Х. Кадиков и другие специалисты-археологи, проводившие исследования в регионе [16. Л. 28].

Отсутствие научно обоснованной классификации и критериев оценки вело к сокращению списков охраняемых объектов, исключению некоторых из них из перечней и др. Для решения данной проблемы Инспекцией ВООПИК разработаны Основные положения для отбора памятников истории и культуры, подлежащих государственной охране.

В 1966 г. в Алтайском крае прошла первая региональная конференция ВООПИК [17], на которой одной из основных была обозначена проблема учета памятников археологии. Продолжались работы по выявлению и изучению таких объектов, проводились исследования на комплексах, находившихся в аварийном состоянии. Для более эффективных действий в данном направлении предлагалось провести работу по составлению карты археологических объектов (в первую очередь это касалось курганов), которые следовало вывести из системы землепользования [15. Л. 15]. На конференции Советом краевого отделения ВООПИК были обозначены основные критерии для отбора памятников истории и культуры, подлежащих государственной охране. Для археологических объектов в первую очередь предлагалось учитывать следующие факторы: значимость в решении вопросов развития материальной культуры и техники; значение памятника при изучении экономической, социальной, политической и культурной истории народов РСФСР, истории образования Российского государства; наличие на памятнике культурного слоя значительной мощности и хорошей сохранности, с четкой стратиграфией и содержащего свидетельства человеческой деятельности. Обязательной охране подлежали памятники археологии, давшие название археологическим культурам, на которых сохранились нераскопанные участки. Обозначенные критерии считались основными для отбора объектов, рекомендованных к постановке под охрану и для проведения их классификации (государственного или местного значения). Однако отмечалось, что в процессе фиксации могут быть выявлены памятники, обладающие и другими значимыми признаками, которые также следует включать в предварительные охранные списки [14. Л. 31]. На каждый объект составлялась учетная документация (паспорт, акт технического состояния и охранное обязательство). Первичным охранным документом являлась учетная карточка ВООПИК.

Анализ отчетных материалов за указанный период показал, что основная деятельность по выявлению и исследованию памятников археологии приходится на конец 1940-х - начало 1950-х гг., когда охранные мероприятия получили соответствующую законодательную базу. Согласно принятым положениям на территории Алтайского края стали проводиться целенаправленные работы по выявлению, регистрации, составлению списков, изучению и паспортизации археологических объектов. Впервые в мероприятия подобного рода включились музеи региона. За короткий период выделено значительное количество новых, ранее неизвестных па- 
мятников, многие поставлены на учет и взяты под охрану. Благодаря проделанной работе стало ясно, что большое количество объектов археологического наследия находится в аварийном состоянии и нуждается в спасении. Специалисты уделяли им особое внимание, осуществлялись специальные раскопки, которые проводились с целью спасения памятников, находящихся под угрозой уничтожения. Информация, полученная об археологических объектах в данный период, сыграла большую роль для дальнейшего их изучения. Однако несмотря на проделанную работу, общая проблема охраны памятников полностью так и не была решена. Начатые мероприятия были прерваны в связи с сокращением списков охраняемых государством объектов и резким снижением ассигнований на реставрационные и восстановительные изыскания. Дальнейшее развитие охраны памятников пришлось на вторую половину 1960-х гг., когда в вопросах сохранения наследия наметились положительные тенденции. Одной из них стала организация ВООПИК. Периодом расцвета Общества считаются 70-80-е гг. XX в., когда оно являлось одной из самых массовых организаций и насчитывало в своих рядах более 10 млн человек [18], тем не менее сам факт создания подобного объединения и первые мероприятия по сохранению наследия в 1960-е гг. обозначили основные направления работ в последующем.

\section{Лuтература}

1. О мерах по улучшению охраны памятников культуры : постановление Совета Министров СССР от 14 октября 1948 г. // Собрание постановлений и распоряжений Совета Министров СССР. М., 1948. № 6. Ст. 81. С. 136-144.

2. Каширина Л. В. Мероприятия по охране памятников археологии на Алтае в 1940-х гг. // Сохранение и изучение культурного наследия Алтайского края. Барнаул, 2006. Вып. 15. C. $77-79$.

3. Паршикова Т.С. Археологические исследования на Алтае в 1940-е годы // Археология, этнография, палеоэкология Северной Евразии: проблемы, поиск, открытия: материалы 51-й Региональной (7-й Всероссийской) археолого-этнографической конференции студентов и молодых ученых. Красноярск, 2011. С. 33-35.

4. Паршикова Т.С. История археологических исследований на Алтае в 1950-е гг. // Вестн. алтайской науки. 2014. № 4 (22). С. 426-428.

5. Паршикова Т.С. Деятельность музеев Алтайского края в области археологии (1940-1960-е гг.) // Изв. Алт. гос. ун-та. Сер.: История, политология. 2013. №4/2 (80). С. 223-227.

6. Краевое государственное казенное учреждение «Государственный архив Алтайского края» (КГКУ ГААК). Ф. 1041. Оп. 1. Д. 113.

7. КГКУ ГААК. Ф. 1041. Оп. 1. Д. 47.

8. КГКУ ГААК. Ф. 1041. Оп. 1. Д. 105.

9. Тишкин А.А. Встречи с А.П. Уманским // Вопр. археологии и этнографии Сибири: памяти профессора А.П. Уманского. Барнаул, 2008. С. 179-207.

10. КГКУ ГААК. Ф. 1041. Оп. 1. Д. 106.

11. КГКУ ГААК. Ф. 1041. Оп. 1. Д. 34.

12. КГКУ ГААК. Ф. 1041. Оп. 1. Д. 379.

13. Голотин И.В. Государственная политика в области охраны памятников истории и культуры в 1953-1985 гг. (по материалам Ярославской области): автореф. дис. ... канд. ист. наук. Ярославль, 2011. 24 с.

14. КГКУ ГААК. Ф.Р. 1549. Оп. 1. Д. 1.

15. КГКУ ГААК. Ф.Р. 1594. Оп. 1. Д. 4.

16. КГКУ ГААК. Ф. 1041. Оп. 1. Д. 726.

17. КГКУ ГААК. Ф.Р. 1549. Оп. 1. Д. 2. 
18. История ВООПИиК [Электронный ресурс]. URL: http://www.voopik.ru/voopiik/history/ (дата обращения: 05.05.2015).

Parshikova Tatiana S. Altai State University. E-mail: taty-parshikova@yandex.ru

DOI $10.17223 / 22220836 / 18 / 7$

\section{ARCHAEOLOGICAL HERITAGE OF ALTAI: THE STUDY AND CONSERVATION IN THE 1940s - 1960s.}

Keywords: archeology, Altai, historical and cultural heritage, expeditions, protection of sites, VOOPIK.

An important trend in the conservation of historical and cultural heritage is the identification, classification and study of archaeological sites. In the territory of Altai such work is carried out over more than 150 years. After the end of World War II, the issue of heritage conservation has become particularly relevant. Leadership of the country noted that there were serious drawbacks in the protection of cultural relics. At the end of the 1940s released a series of decisions concerning the identification, research, accounting, conservation of archaeological sites. Guided by the provisions, responsible for the execution of works in the Altai Territory organizations had worked on the identification, registration, and certification of lists of sites of historical and cultural heritage. In this case, the active role played by archaeologists who conducted the research in the region, the museum staff, the local intellectuals. In a short time it was recorded a significant number of different sites. In the late 1940s - early 1950s. security measures have received an appropriate legislative framework. The information obtained about the heritage sites in this period, played an important role for further study. However, the activity started was interrupted by narrow the list of objects protected by the state and a sharp decrease in the provision for restoration and reconstruction work. Further development of the sites protection in the second half of the 1960s, when the All-Russian Society for Historic Conservation and Cultural Organization (VOOPIK) was organized. Society has become the first non-governmental actors in the conservation of heritage, unites not only the local history enthusiasts, but above all, specialists in various fields. One of the main question remained accounting sites, as the lack of evidence-based classification and evaluation criteria led to the reduction of the list of protected sites, the exclusion of some of the lists. The essential problem is the lack of qualified specialists able to carry out all the activities to identify, study, conservation and promotion of sites. In the early years of the organization has made measures to improve the business of protection of historical and cultural heritage, has developed a number of documents to facilitate more effective work in this direction. Considerable attention was paid to the archeological objects. The information obtained about the heritage sites in this period, played an important role for further study. With the establishment of the Society and its operations at the end of 1960. specific measures have been taken for the conservation of sites.

\section{References}

1. O merah po uluchsheniju ohrany pamjatnikov kul'tury : postanovlenie Soveta Ministrov SSSR ot 14 oktjabrja 1948 g. // Sobranie postanovlenij i rasporjazhenij Soveta Ministrov SSSR. M., 1948. № 6. St. 81. S. 136-144.

2. Kashirina L. V. Meroprijatija po ohrane pamjatnikov arheologii na Altae v 1940-h gg. // Sohranenie i izuchenie kul'turnogo nasledija Altajskogo kraja. Barnaul, 2006. Vyp. XV. S. 77-79.

3. Parshikova T.S. Arheologicheskie issledovanija na Altae v 1940-e gody // Arheologija, jetnografija, paleojekologija Severnoj Evrazii: problemy, poisk, otkrytija: materialy LI Regional'noj (VII Vserossijskoj) arheologo-jetnograficheskoj konferencii studentov i molodyh uchenyh. Krasnojarsk, 2011. S. 33-35.

4. Parshikova T.S. Istorija arheologicheskih issledovanij na Altae v 1950-e gg. // Vestnik altajskoj nauki. 2014. № 4 (22). S. 426-428.

5. Parshikova T.S. Dejatel'nost' muzeev Altajskogo kraja v oblasti arheologii (1940-1960-e gg.) // Izvestija Altajskogo gosudarstvennogo universiteta. Ser.: Istorija, politologija. 2013. №4/2 (80). S. 223-227.

6. Kraevoe gosudarstvennoe kazennoe uchrezhdenie «Gosudarstvennyj arhiv Altajskogo kraja» (KGKU GAAK). F. 1041. Op. 1. D. 113.

7. KGKU GAAK. F. 1041. Op. 1. D. 47. 
8. KGKU GAAK. F. 1041. Op. 1. D. 105.

9. Tishkin A.A. Vstrechi s A.P. Umanskim // Voprosy arheologii i jetnografii Sibiri: pamjati professora A.P. Umanskogo. Barnaul, 2008. S. 179-207.

10. KGKU GAAK. F. 1041. Op. 1. D. 106.

11. KGKU GAAK. F. 1041. Op. 1. D. 34.

12. KGKU GAAK. F. 1041. Op. 1. D. 379.

13. Golotin I.V. Gosudarstvennaja politika v oblasti ohrany pamjatnikov istorii i kul'tury v 1953 1985 gg. (po materialam Jaroslavskoj oblasti): avtoref. dis. ... kand. ist. nauk. Jaroslavl', 2011. 24 s.

14. KGKU GAAK. F.R. 1549. Op. 1. D. 1.

15. KGKU GAAK. F.R. 1594. Op. 1. D. 4.

16. KGKU GAAK. F. 1041. Op. 1. D. 726.

17. KGKU GAAK. F.R. 1549. Op. 1. D. 2.

18. Istorija VOOPIiK [Jelektronnyj resurs]. URL: http://www.voopik.ru/voopiik/history/ (data obrashhenija: 05.05.2015). 